\title{
Determination of Biochemical and Histological Parameters of Alcohol Administration in Wistar Rats
}

\author{
O. G. Dawodu ${ }^{1,2^{*}}$, O. A. T. Ebuehi ${ }^{1}$, O. S. Odesanmi ${ }^{1}$ and M. O. Olalekan ${ }^{2}$ \\ ${ }^{1}$ Department of Biochemistry, College of Medicine, University of Lagos, Idi-Araba, Lagos, Nigeria. \\ ${ }^{2}$ Department of Science Laboratory Technology, Federal Polytechnic Ede, Osun State, Nigeria.
}

\section{Authors' contributions}

This work was carried out in collaboration among all authors. Author OGD designed the study, performed the statistical analysis, wrote the protocol and wrote the first draft of the manuscript. Authors OATE and OSO managed the analyses of the study. Author MOO managed the literature searches. All authors read and approved the final manuscript.

Article Information

DOI: $10.9734 / A R R B / 2019 / v 32 i 630102$ Editor(s):

(1) Dr. Paola Angelini, Department of Applied Biology, University of Perugia, Perugia, Italy. (2) Dr. J. David Puett, Professor, Department of Biochemistry and Molecular Biology, University of Georgia, Athens, USA.

Reviewers:

(1) Weena Koeypudsa, Chulalongkorn University, Thailand. (2) Nilgün Kuşçulu, Kayseri University, Turkey. (3) Christopher Chiedozie Mbadugha, University of Uyo, Nigeria. (4) Eguaoje Abiodun Stanley, Ambrose Alli University, Nigeria. Complete Peer review History: http://www.sdiarticle3.com/review-history/48346

Original Research Article

Received 13 May 2019

Accepted 07 July 2019 Published 26 August 2019

\begin{abstract}
Animal model development of alcohol administration in rats is of crucial importance as it gives indirect information to effects of alcohol in humans. An indirect assessment of this would be the biochemical and histological data that could arise from such experiments.

20 Male Wistar rats weighing $(63.50 \pm 3.79 \mathrm{~g})$, were divided into four groups (consisting 15 treated animals and 5 control animals) and administered with varying concentrations of ethanol (5\% $15 \%$ and $40 \%$ ) via intragastric intubation for a period of 28 days. Probic evaluations, liver biochemical enzymes and alteration in histology profile of gastrointestinal tract (GIT) and viscera organs (namely the liver, kidney, heart and lungs) were determined after experimental duration.

At $40 \%$ ethanol administration, the rats showed biochemically significant decrease in serum gamma glutamyl transferase (GGT), serum aspartate (AST) and Alanine amino transferase (ALT) when compared to normal study while $5 \%$ and $15 \%$ ethanol administered rats were comparable with control values i.e. normal study. Probic evaluations such as body weight, water intake and food
\end{abstract}


intake showed percentage decrease in $40 \%$ ethanol administrated rat when compared with controls. The photomicrographs of the $5 \%$ and $15 \%$ ethanol administered rats indicated mild damage in their histological profiles when compared to the normal study while there was more adverse damage occurring in the $40 \%$ ethanol administrated rats.

Conclusion: From this study, serum aspartate (AST), gamma glutamyl transferase (GGT) and Alanine amino transferase (ALT), probic evaluation (body weight, food intake and water intake) coupled with histopathological investigation may be used as biomarker for the early diagnosis of ethanol toxicity in human beings.

Keywords: Alcohol; biomarkers; histopathology; growth performance index.

\section{INTRODUCTION}

Over the centuries, alcohol has become the most socially-accepted addictive drug worldwide [1]. Its use antedates recorded history and may go back as far as the Neolithic age around 8000BC. Ethanol is found associated with varieties of our cultural life, various names have been ascribed to it. Among them are; whisky in Gallic, water of life, Sapele water, gin, ogogoro, ojuna etc has been the nomenclature of alcohol in various regions and spheres. Ethanol is the type of alcohol found in alcoholic beverages (wine, beer and spirit).

Alcohol is a beverage consumed by man since time immemorial. Alcohol administration in animals is a means by which alcohol usage, advantages and disadvantages can be studied in detail as a means of simulating human alcohol consumption. Mice and rats till date are the most common animals used in studying alcohol induced organ damage and the reason stems from their well-defined genetic background and availability in diverse genetic traits, and their nearness to humans in terms of evolutionary background [2]. Animal models stems to view aspects of human alcohol consumption, parameters such as biochemical markers and histology go a long way in assessing such characteristics. Biochemical markers such as liver function test indices; ALT, AST and ALP help to assess the metabolism opf alcohol in the body as the liver is the main organ for alcohol metabolism. Histology on the other hand sometimes gives information not clearly seen in serum assessment of alcohol. Using hematoxylin-eosin (H\&E) staining techniques, cellular components are revealed and clear distinction between normal and somewhat diseased or affected organs are viewed [3]. Alcohol is miscible with water and its diffusion in the body systems is so assured that every organ is a target for alcohol. Acute or chronic alcohol consumption has been found to cause degeneration of organs in adults $[4,5,6,7]$. Long- term use of alcohol in excessive quantities is capable of damaging practically every organ system in the body [8,9]. Alcohol biomarkers have important applications in medicine and public safety [10]. The aim of this study was to determine the biochemical and histological parameters of alcohol administration in Wistar rats.

\section{MATERIALS AND METHODS}

\subsection{Animal Collection}

Twenty Wistar rats with mean weight $63.50 \pm 3.79$ $\mathrm{g}$ were obtained from breeding stock maintained in the animal house of the College of health sciences, Osun State University Osogbo main campus (UNIOSUN) and were authenticated by the farm Director UNIOSUN.

The animals collected were house in wellventilated wired plastic metabolic cages in the animal facility of the department of Biochemistry, Federal Polytechnic Ede, and approval was obtained from the Departmental Ethical Committee on animal usage.

The rats were maintained under standard room temperature $\left(25^{-} 26^{\circ} \mathrm{C}\right)$ and humidity of $65.5 \%$. They were allowed unrestricted access to water and rat chow (Tina Livestock feeds Ltd, Oke Gada Ede Osun state Nigeria).

They were allowed to acclimatize for a period of 21 days before the commencement of experiments, the weight of the animals were estimated at procurement, during acclimatization, at commencement of the experiment and every day throughout the duration of the experiments using an electronic analytical precision balance.

\subsection{Experimental Design}

Twenty male Wistar rats weighing $63.50 \pm 3.79 \mathrm{~g}$ were used for this study. They were divided into 4 groups of 5 rats each, $1^{\text {st }}$ group served as the 
control administered saline, $2^{\text {nd }}-4^{\text {th }}$ groups were administered $5 \%, 15 \%$ and $40 \%$ ethanol respectively for 28 days by intra-gastric administration. All animals had access to rat chow and water ad libitum.

Animal experiments complied with the ARRIVE guidelines and was carried out in accordance with the U.K. Animals (Scientific Procedures) Act, 1986 and associated guidelines, EU Directive 2010/63/EU for animal experiments, was strictly followed throughout the experiment.

\subsection{Animal Sacrifice and Sample Collection and Preparation}

On the $29^{\text {th }}$ day of the experiment, the rats were fasted overnight, sacrificed via cervical dislocation. Blood samples were collected via cardiac puncture, into plain tubes, centrifuged at $3000 \mathrm{~g}$ for $5 \mathrm{~min}$, and serum collected and stored at $-20^{\circ} \mathrm{C}$ for further analysis. The liver, kidney, heart and lungs i.e. the viscera organs, were excised and fixed in 10\% formal-saline for histopathological interpretations [11].

\subsection{Estimation of Biochemical Parameters}

The methods of Reitman and Frankel [12] and Hammed [13] were used for the determination of alanine amino transferase (ALT) and aspartate amino transferase (AST) respectively, while that of Szasz [14], Hyder et al. [15] was used for the determination of gamma glutamyl transferase (GGT) in the serum.

\subsection{Determination of Volume of Alcohol and Route of Administration}

The ethyl alcohol used in this study was reagent grade $200 \%$ proof. The volume of alcohol administered to the animals was calculated using the Widmark [16] formula modified by Bouwer [17]. Alcohol concentrations used in this study was $10-30 \%$ to represent the three classes of alcoholic beverages commonly consumed by man. Less than $10 \%$ alcoholic beverage content represent beers, while $10-20 \%$ represents the wine group while $30 \%$ and above represents the spirit group.

\subsection{Histological Procedure and Analysis}

This was done as described by Saalu et al. [11], briefly, the organs were cut on slabs about 0.5 $\mathrm{cm}$ thick and fixed in $10 \%$ formal saline for a day after which they were transferred to $70 \%$ alcohol for dehydration the tissues, after which the same tissues were passed through $90 \%$ alcohol and $10 \%$ chloroform for different durations before they were transferred into two changes of molten paraffin wax for 20 min each in an oven at $57^{\circ} \mathrm{C}$. Serial selections of $5 \mathrm{~mm}$ thick were obtained from a solid block of tissues and were stained with haematoxylin and eosin stains, after which they were passed through a mixture of equal concentration of xylene and alcohol. Following clearance in xylene, the tissues were oven-dried; photomicrographs were taken with a colour digital camera mounted on a light microscope.

\subsection{Statistical Analysis}

The SPSS v. 25.0 computer software package (SPSS Inc. Chicago, U.S.A) and GraphPad Prism 7.0 were used for this study. The results are presented as mean \pm standard error of the mean $(X \pm S E M)$.

\section{RESULTS AND DISCUSSION}

The effect of ethanol on the body weight was assessed in this study; Table 1 showed the changes in body weight of rats before and after administration of ethanol solutions. Here the weight observed in intoxicated rats recorded a significant decrease by $3.6 \%, 1.9 \%$ and $1.3 \%$ as compared to controls. This was in accordance with the study of Rajakrishnan et al. [18] who found out that changes in the body weight of the rat may be due to the deposition of lipids in adipose tissue and fluid accumulation in the organ. Ethanol adds empty calories to the body, hence administration of it to the animals led to the increase in weight observed across groups.

The effect of water intake level in association with ethanol administration revealed that the higher the ethanol concentration the more the water intake in comparison to the control group. Significant differences in daily food intake were observed between control and alcohol treated rats utilizing oral administration of alcohol, this was in line with the previous study of Callaci et al. [19] who observed a significant difference between controls and alcohol administered rats.

Alcohol (ethanol) may lead to hepatotoxicity; ALT, AST, and GGT are most commonly used makers of hepatocyte injury, they are more specific enzymes biomarkers in intoxication experiments [20]. Ethanol administrated rats recorded a significant increase in gammaglutamyl transferase (GGT), Aspartate amino transferase (AST), Alanine amino transferase by; 
GGT $(1.2 \%, 0.2 \%$ and $0.5 \%)$ AST $(0.13 \%, 0.1 \%$ and $5.21 \%)$ and $\operatorname{ALT}(0.11 \%, 0.21 \%$ and $11.49 \%$ ) following the administration of various concentrations of ethanol solutions (Table 2) as compared to the control group respectively.

In agreement with the present study, Chen et al. [21] observed a significant increase in AST and ALT levels after moderate drinkers (at least once per month., < $210 \mathrm{~g}$ ethanol/week for men <140 g ethanol/week for women). In addition, Onyesom and Anosike [22] recorded elevation in AST and
$\mathrm{ALT}$ in rabbit orally given $1.5 \mathrm{~g}$ ethanol/ $\mathrm{kg}$ body weight as single daily dose for a continuous period of fifteen weeks. The increase in enzyme activity was mainly due to the effect of ethanol that interpolates and expands biomembranes leading to increased membrane fluidity and enzyme release [23]. Following the treatment with alcohol, there were significant elevations in GGT, AST and ALT (Group C, 40\% Ethanol) which confirms the likely hepatotoxic effect of alcohol. This finding is in line with the report of Maher [24].

Table 1. Body weight, feed and water intake of rats administered alcohol for 28 days

\begin{tabular}{lllll}
\hline Probic Indices & Control & 5\% EtOH & 15\% EtOH & 40\% EtOH \\
\hline B.W (g) & $85.33 \pm 11.52$ & $89.67 \pm 10.04$ & $79.33 \pm 8.95$ & $73.50 \pm 6.99$ \\
H.I (ml) & $90.00 \pm 33.15$ & $88.67 \pm 21.06$ & $62.00 \pm 27.68$ & $53.17 \pm 10.33$ \\
F.I (g) & $90.00 \pm 7.46$ & $79.33 \pm 9.86$ & $67.33 \pm 16.45$ & $37.17 \pm 14.93$ \\
\hline
\end{tabular}

Data are expressed as mean \pm standard error of the mean (SEM) of five normal and 15 intoxicated rats. Key: B.W-Body Weight, H.I- $\mathrm{H}_{2} \mathrm{O}$ Intake, F.I-Feed Intake
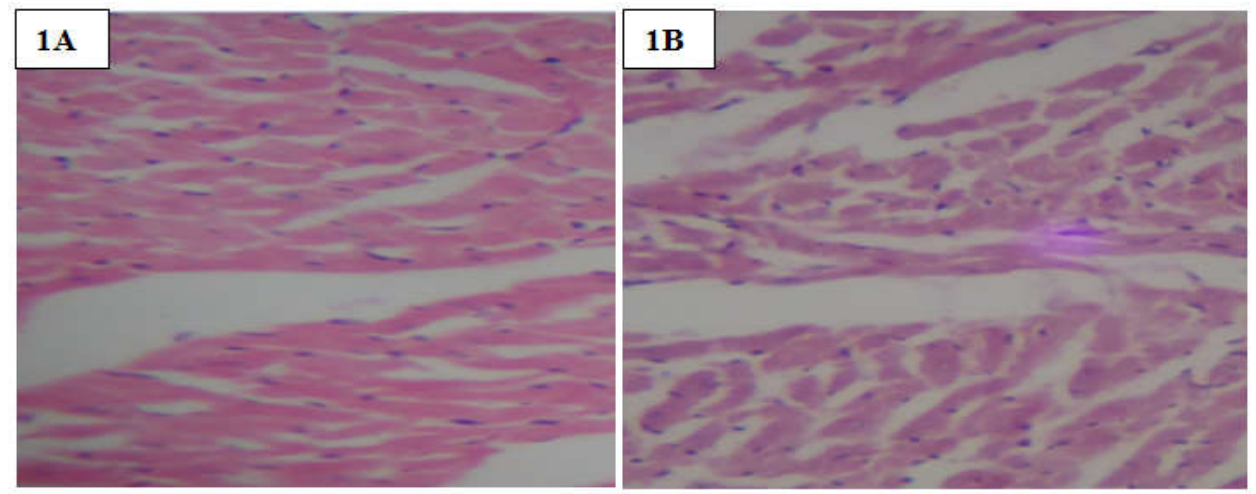

Plate 1. Photomicrographs of Heart of alcohol administered rats (H\&E, 100x)

$1 A \& 1 B$ : Control rats and rats administered $40 \%$ etoh showing normal study i.e. normal heart architecture Key: A: Control, B: $40 \% \mathrm{EtOH}$
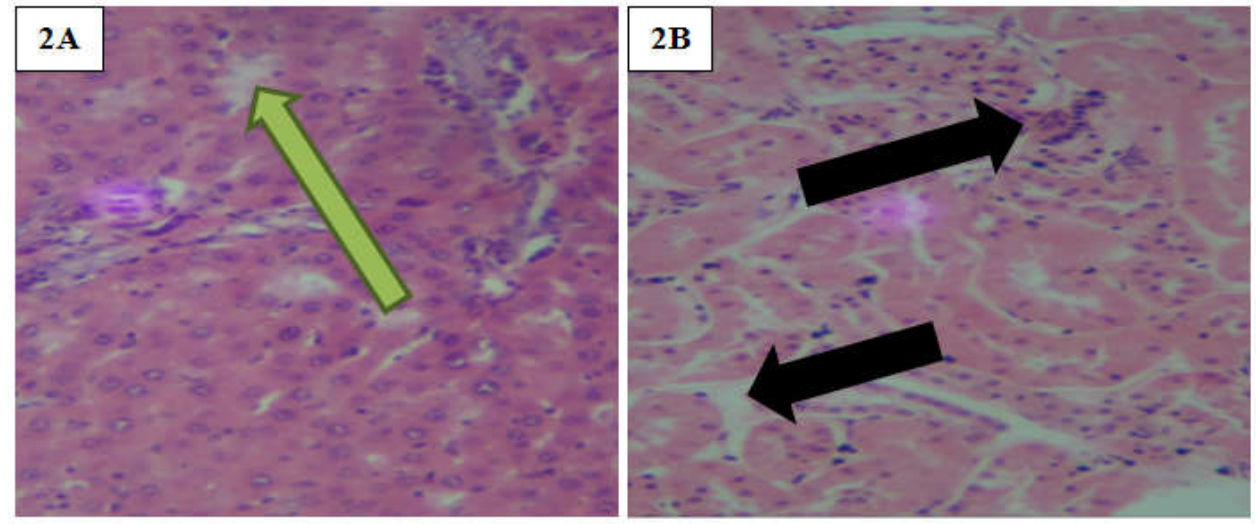

Plate 2. Photomicrographs of Liver of alcohol administered rats. (H\&E, 100x)

2A: Well preserved liver architecture showing normal appearing portal tract (green arrow) 2B: Normal study with ghostlike appearance of the tubules (black arrow).

Key: A: Control, B: $15 \%$ EtOH 

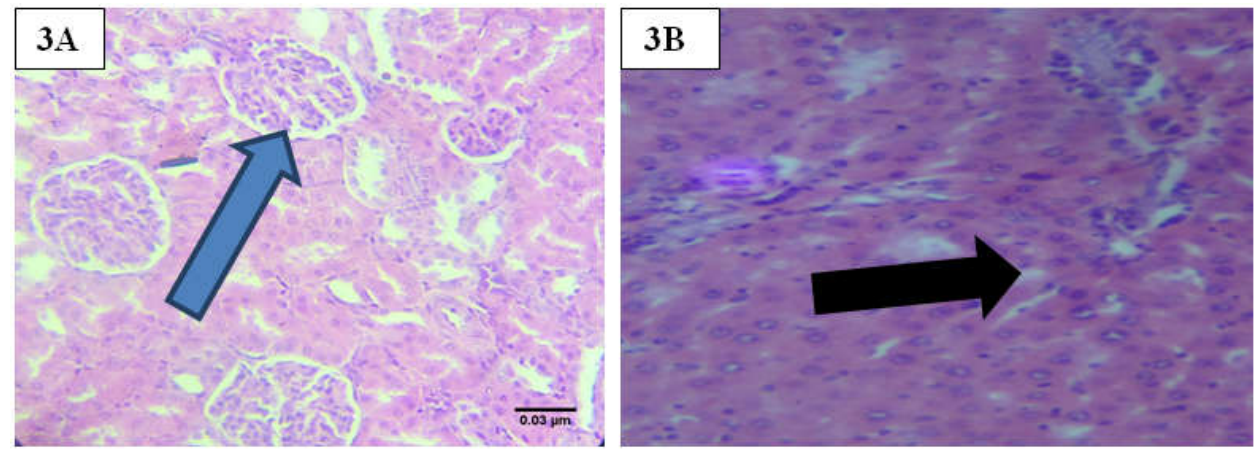

Plate 3. Photomicrographas of Kidney of alcohol administered rats (H\&E, 100x)

3A: Normal glomeruli $G$ and tubules $T$ in Kidney i.e. normal study, i.e. the glomeruli $G$ appears normal with obvious central vein.

3B: At 15\% ethanol concentration sloughing off of cells that lines tubules, a sign of ATN i.e. acute tubular necrosis.

Key: A- Control B-15\% etoh
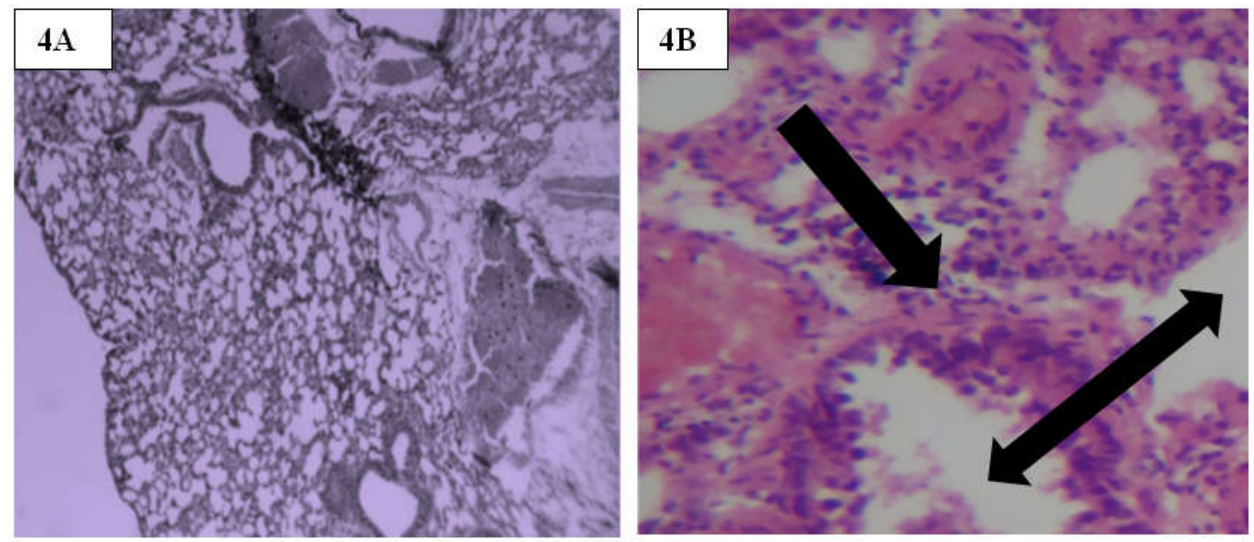

Plate 4. Photomicrographs of Lungs of Alcohol Administered Rats (H\&E, 100× A. 400×B)

4A: Normal lungs showing clear alveolar spaces i.e. normal study

4B: Intense inflammatory cells within the interstitium and congestion (black arrows)

Key: A:Control, B: $40 \% \mathrm{EtOH}$

Table 2. Serum activities of ALT, AST \& GGT of rats administered alcohol for 28 days

\begin{tabular}{lllll}
\hline Parameters & Control & $\mathbf{5 \%}$ EtOH & $\mathbf{1 5 \%}$ EtOH & $\mathbf{4 0 \%}$ EtOH \\
\hline GGT(U/L) & $148.16 \pm 4.86$ & $151.19 \pm 5.11$ & $152.36 \pm 8.44$ & $158.36 \pm 8.44$ \\
AST(U/L) & $433.09 \pm 1.66$ & $719.70 \pm 2.40$ & $725.45 \pm 8.79$ & $733.03 \pm 15.95$ \\
ALT(U/L) & $152.20 \pm 3.40$ & $256.49 \pm 8.01$ & $257.43 \pm 1.55$ & $258.43 \pm 9.64$ \\
\hline
\end{tabular}

Data are expressed as mean \pm standard error of the mean (SEM) of five normal and 15 intoxicated rats.

Key: EtOH-ethanol, ALT-Alanine amino transferase, AST- Aspartate amino transferase, GGT-Gamma glutamyl transferase

The evaluation of liver function by measuring serum GGT, AST and ALT of alcohol intoxicated rat can be used for the study of human consumption because most of the alcohol consumed by people is metabolized by the liver. Therefore, the liver is constantly saddled with the responsibility of detoxifications of substances ingested. It is documented that a number of potentially dangerous by-product are generated [24] these by-products especially free radicals are known to cause destruction of the liver cell hence elevation of ALT, AST and GGT [25].

This study examined the slides of Heamatoxlin and Eosin (H\&E) stained tissues of the liver, 
kidney, heart and lungs of all the study animals that received $(5 \%, 15 \%, 40 \%)$ ethanol and the control group that received $0.9 \%$ normal saline. The major histopathological changes occurred in organs of animals that received $40 \%$ ethanol, there were minimal histopathological changes in the organ tissues of the rat received $5 \%$, and $15 \%$ ethanol indicated that high concentration of ethanol is required to caused significant histopathology changes in the liver, kidney, heart and lungs.

In all the experimental groups that received alcohol, none of the heart tissue showed significant degeneration in histology profile when compared to the control group that received normal saline. The liver tissues of $15 \%$ alcohol administered rats showed well preserved liver architecture with normal appearance in the portal tract when compared with the liver tissues of the control, this was in agreement with Adedapo et al. [26] who observed no abnormal features in the histopathology examination of the liver tissue. This could have been caused by low doses used in the study. The kidney tissues that received $15 \%$ ethanol showed sloughing off of cells that line tubules with some ghostlike appearance of the tubules causing acute tubular necrosis. This was in accordance with the findings of Kasolo et al. [27] that the kidney tissue showed expanded and congested glomeruli, mononuclear cellular infiltration which are features of mild nephritis that caused kidney tissue damage followed moderate ethanol intake.

Alcohol detoxification in the body is majorly carried out by the liver. The present study revealed that liver damage is not a consequence of alcohol concentration as any level may cause damage in different forms. The kidney's major function is basically water and electrolyte balance. Renal damage has been found to be associated with acute intoxication or chronic alcoholism [28,29].

Histopathological investigation of lungs that received highest concentration of ethanol $40 \%$ showed intense inflammatory cells within the interstitium and congestion. This present study was in agreement with previous study on alcohol where acute histopathological change in lungs, kidney and liver were documented at $45 \%$ alcohol for 4 weeks [30].

Gradual mortality was observed following ethanol administration into rat with regard to varying concentrations of ethanol. There were progressive toxic signs and symptoms which resulted in pre-terminal death. Gross pathological symptoms were observed in the rat of highly concentrated ethanol treated rat. There was an observation of gross abnormality that could be attributed to ethanol administration at the time of autopsy.

\section{CONCLUSION AND RECOMMENDA- TION}

Though moderate alcohol intake have shown beneficial effect, administration of different concentrations of alcohol in this study caused different alteration to the visceral organs such as liver, kidney, heart and lungs. Varying concentrations of ethanol intoxication also leads to disturbances of certain metabolic parameters that can be used as makers for early detection of ethanol toxicity.

\section{ETHICAL APPROVAL}

Ethical approval for the study was obtained from Ethics Review Committee of College of Medicine University of Lagos, Idi-Araba with CMUL HREC REGISTRATION NUMBER: HREC/15/04/2015.

\section{COMPETING INTERESTS}

Authors have declared that no competing interests exist.

\section{REFERENCES}

1. Ohkubo T, Metoki H, Imai Y. Alcohol intake circadian blood pressure variation, and stroke. Hypertension. 2009;53:45.

2. D'Souza El-Guindy NB, Kovacs EJ, De Witte P, Spies C, Littleton JM, de Villiers WJS, Lott AJ, Plackett TP, Lanzke N, Meadows GG. Laboratory models available to study alcohol-induced organ damage and immune variations; choosing the appropriate models. Alcohol Clinical Experimental Research. 2010;34(9):14891511.

3. Gurcan MN, Boucheron L, Can A, Madabhushi A, Rajpoot N, Yener B. Histopathological image analysis: A review. IEEE Reviews of Biomedical Engineering. 2009;2:147-171.

4. Mezey E. Metabolic effects of alcohol. Federation Proceedings. 1985;44(1):134138. 
5. Brailowsky S, Garcia O. Ethanol, GABA and Epilepsy. Archives of Medical Research. 1999;30(1):3-9.

6. Fortunato F, Gates LK. Alcohol feeding and lipopolysaccharide injection modulate apoptotic effectors in the rat pancrese in vivo. Pancreas. 2000;21(2):174-180.

7. Watabiki T, Okii Y, Tokiyasu T, Yoshimura S, Yoshida M, Akane A, Shikata N, Tsubura A. Long term ethanol consumption in ICR mice causes mammary tumor in females and liver fibrosis in males. Alcoholism Clinical and Experimental Research. 2000;4(4):117S$122 S$.

8. Ponnapa BC, Rubin E. Modeling Alcohol's effects on organs in animal models. Alcohol Research and Health. 2000;24(2): 93-104.

9. Testino G. Alcoholic diseases in hepatogastroenterology: A point of view. Hepatogastroenterology. 2008;55(82-83): 371-7.

10. Litten RZ, Fertig J. Self-report and biochemical measures of alcohol consumption. Addiction. 2003;98(2):3-4.

11. Saalu LC, Jewo PI, Fadeyebi LO, Ikuerowo SO. The effect of unilateral vericocele on contralateral testicular histo-morphology in Rattus norvegicus. Journal of Medical Science. 2008;8(7):654-655.

12. Reitman S, Frankel S. A colorimetric method for the determination of serum glutamic oxaloacetic and glutamic pyruvic transaminases. American Journal Clinical Pathology. 1957;28:56-63.

13. Hammed MA. Metabolic profile of rats after one hour of intoxication with a single oral dose of ethanol. Journal of Pharmacology and Toxicology. 2011;6:158-165.

14. Szasz G. A kinetic photometric method for serum gamma glutamyl transpeptidase (GGT). Clinical Chemistry. 1969;15(2):12436.

15. Hyder MA, Hassan M, Mohieldein $A H$. Comparative levels of ALT, AST, ALP and GGT in liver associated diseases. European Journal of Experimental Biology. 2013;3(2):280-284.

16. Widmark EMP. Principles and applications of medicolegal alcohol determination. Davis, CA: Biomedical Publications. 1981;163.

17. Brouwer IG. The Widmark formula for alcohol quantification. Journal of the South African Dental Association. 2004;59:427428.
18. Rajakrishnan $\mathrm{V}$, Viswanathan $\mathrm{P}$, Menon VP. Adaptation of siblings of female rats given ethanol: Effect of $\mathrm{N}$ - acetyl - L cysteine. Amino Acids. 1997;12:323-41.

19. Callaci JJ, Juknelis D, Patwardhan D, Wezeman $\mathrm{FH}$. Binge alcohol treatment increases vertebral bone loss following ovariectomy; compensation by intermittent parathyroid hormone. Alcohol Clinical and Experimental Research. 2006;30(4):665672.

20. Palmer RB. A review of the use of ethyl glucuronide as a marker for ethanol consumption in forensic and clinical medicine. Seminars in Diagnostic Pathology. 2009;26(1):18-27.

21. Chen J, Conigrave KM, Mascaskill P, et al. On behalf of the World Health Organization and the International Society for Biomedical Research on Alcoholism Collaborative Group. Combining carbohydrate-deficient transferrin and gamma-glutamyl transferase to increase diagnostic accuracy for problem drinking. Alcohol and Alcoholism. 2003;38(6):574582.

22. Onyesom I, Anosike EO. Changes in rabbit liver function markers after chronic exposure to ethanol. Asian Journal of Biochemistry. 2007;2:337-342.

23. Yang SC, Huang JR, Chen CL, Chiu MJ, Shieh SJ. Regulation of total serum protein; Effect of antioxidant capacity on isolated rat hepatocytes. World Journal of Gastroenterology. 2005;11:7272-7276.

24. Maher JJ. Exploring alcohol's effects on liver function. Alcohol Health Research World. 1997;21(1):5-12.

25. Onyesom EO, Atakuo. An investigation into the relationship between alcoholinduced changes in serum triacylglycerol and blood pressure. Nigerian Journal of Biochemistry and Molecular Biology. 1998;13:79-83.

26. Adedapo AA, Mogbojuri OM, Emikpe BO. Safety evaluations of the aqueous extract of Moringa oleifera in rats. Journal of Medicinal Plants Research. 2009;3(8):586591.

27. Kasolo J, Bimenya GS, Lonzy O, OgwalOkeng JW. Sub-acute toxicity evaluation of Moringa oleifera leaves aqueous and ethanol extracts in Swiss Albino rats. International Journal of Medicinal Plants Research. 2011;1(6):75-81.

28. Vamvakas S, Bruening $\mathrm{T}$, Thomasson B, Lammert $M$, Baumueler $A$, Bolt HM, 
Dekant W, Birner G, Henscler D, Ulm K. Renal cell cancer correlated with occupational exposure to trichloroethene. Journal of Cancer Research Clinical Oncology. 1998;126(3):178-80.

29. Dawodu OG, Ebuehi OAT, Odesanmi OS. Comparative safety profiles of pure and alcohol beverages in Wistar rats. British
Journal of Medicine and Medical Research. 2017;20(9):1-11.

30. Abdelgadir EH, Ahmed RH, Adam SLY, Husein AM. Evaluation of toxicological activity (acute and sub chronic toxicities) of Lawsonia innermis seeds on Wistar rats. Journal of Pharmacological Toxicology. 2010;5(7):324-333.

(c) 2019 Dawodu et al.; This is an Open Access article distributed under the terms of the Creative Commons Attribution License (http://creativecommons.org/licenses/by/4.0), which permits unrestricted use, distribution, and reproduction in any medium, provided the original work is properly cited.

Peer-review history:

The peer review history for this paper can be accessed here: http://www.sdiarticle3.com/review-history/48346 